\title{
Histological diagnosis of cytomegalovirus hepatitis in liver allografts
}

\author{
F Colina, N T Jucá, E Moreno, C Ballestín, J Fariña, M Nevado, C Lumbreras, \\ R Gómez-Sanz
}

\begin{abstract}
Aims-To determine the incidence of histologically documented cytomegalovirus (CMV) hepatitis following orthotopic liver transplantation (OLT) and to assess the effectiveness of immunohistochemistry and in situ hybridisation (ISH) in detecting CMV. To describe the histological pattern most frequently associated with CMV hepatitis in order to select the biopsy group in which these modern techniques are most effective.

Methods-A prospective histological study was carried out on 853 biopsy specimens, obtained from 191 liver allografts (160 patients). Specimens were stained with haematoxylin and eosin and immunohistochemically (avidin-biotin complex) using monoclonal antibodies directed against early and late CMV antigens. A retrospective selection was made of 23 specimens with viral inclusion bodies in cytomegalic cells (group A) to characterise the most frequently associated histological pattern, and of 34 other specimens without viral inclusion bodies (group B) but with the same microscopic features as group A. Re-cuts from both specimen groups were studied using immunohistochemistry and ISH with a CMV specific complementary DNA probe.
\end{abstract}

Results-CMV infection was confirmed in 35 specimens (29 by immunohistochemistry, 23 by presence of inclusion bodies in haematoxylin and eosin stained sections, 16 by ISH) from 27 patients (incidence $16 \cdot 9 \%)$. CMV hepatitis was diagnosed within $46 \pm 19$ (range 21-114) days posttransplant. Twenty one $(91 \cdot 3 \%)$ of the 23 biopsy specimens with inclusion bodies (group A) displayed heterogeneous inflammatory foci disseminated throughout the hepatic lobule. Nineteen specimens (82.6\%) were positive by immunohistochemistry and $14(60.9 \%)$ by ISH. In eight $(23.5 \%)$ of the 34 group B specimens CMV infection was confirmed by immunohistochemistry $(n=6)$ or ISH $(n=2)$. Another $12(35.3 \%)$ of the group B specimens negative on staining with haematoxylin and eosin, immunohistochemistry and ISH came from allografts in which previous or subsequent biopsy specimens were CMV positive.

Conclusions-Demonstration of cytomegalic inclusion bodies in haematoxylin and eosin sections is sufficient for a diagnosis of CMV hepatitis. The routine use of immunohistochemistry in all allograft biopsy specimens in more sensitive than demonstration of inclusion bodies by staining with haematoxylin and eosin but may yield false negative results because of the focal distribution of positive cells. ISH was less sensitive than staining with haematoxylin and eosin and/or immunohistochemistry. A histological picture of "disseminated focal hepatitis" without viral inclusion bodies selects a group of allograft biopsy specimens in which immunohistochemistry and/or ISH may improve detection of CMV.

(f Clin Pathol 1995;48:351-357)

Keywords: Cytomegalovirus, liver transplant, hepatitis.

Cytomegalovirus (CMV) is the opportunistic agent which causes greater morbidity than all of the viruses which infect immunocompromised transplant recipients. ${ }^{1-5} \mathrm{CMV}$ infection may lead to allograft dysfunction in orthotopic liver transplants (OLT), and the incidence of CMV allograft hepatitis has been reported at between 4 and $34 \cdot 6 \% .^{5-12}$ Several factors ${ }^{11}$ are responsible for this wide range of incidences. The immunosuppressive regimen, ${ }^{5}$ differences in the proportion of CMV seronegative recipients of a liver from CMV seropositive donors, ${ }^{6}$ and the use of antiviral prophylaxis are three of the most important factors. ${ }^{11}$

Allograft biopsy may be necessary for establishing a diagnosis of CMV hepatitis ${ }^{10}$ and the presence of CMV in liver tissue can be documented by several histopathological techniques. ${ }^{13}$ The demonstration of cytomegalic inclusion bodies in routine haematoxylineosin stained sections has been regarded as the gold standard for assessing the sensitivity of immunohistochemistry with anti-CMV antibodies, of in situ hybridisation (ISH) with a CMV specific complementary DNA probe, ${ }^{14}$ and of the rapid shell vial culture. ${ }^{613} \mathrm{Im}$ munohistochemistry and/or ISH can be used routinely, either separately or together, in liver allograft biopsy specimens. These two techniques may demonstrate the presence of the virus in some cases in which its characteristic viral inclusion bodies are not detected by staining with haematoxylin and eosin. ${ }^{13-16}$ However, the routine use of these techniques in all liver allograft biopsy specimens is expensive and time-consuming.

One aim of this study was to evaluate comparatively the sensitivity and effectiveness of each of the three histopathological methods (staining with haematoxylin and eosin,
Correspondence to: Dr F Colina.

Accepted for publication 1 July 1994 
Table 1 Incidence and number of days post-OLT to diagnosis of CMV hepatitis distributed by positive histopathology

\begin{tabular}{lllllll}
\hline Method & No. of patients & Days post-OLT (range) & $\begin{array}{l}\text { No. of } \\
\text { specimens (s) }\end{array}$ & Days post-OLT (range) \\
\hline Haematoxylin and eosin & 20 & $44 \pm 11$ & $(21-61)$ & $23(0 \cdot 66)$ & $43 \pm 10$ & $(21-61)$ \\
Immunohistochemistry & 24 & $47 \pm 19$ & $(23-114) *$ & $29(0 \cdot 83)$ & $59 \pm 62$ & $(23-373)$ \\
In situ hybridisation & 14 & $47 \pm 15$ & $(25-88)$ & $16(0 \cdot 46)$ & $50 \pm 15$ & $(25-88)$ \\
Total positive & 27 & $46 \pm 19$ & $(21-114)$ & 35 & $59 \pm 57$ & $(21-373)$
\end{tabular}

*If one patient is excluded (outlier from day 114), the $x \pm \sigma$ for IHC is $44 \pm 13$ (range 23-73) ( $n=23$ ); $s=$ sensitivity (number of positives/total number of positive biopsy specimens)

immunohistochemistry, ISH) for diagnosing CMV hepatitis in a series of liver allograft biopsy specimens. In CMV hepatitis viral inclusion bodies are normally accompanied by other microscopic lesions in immunocompetent and immunosuppressed patients. ${ }^{910}$ Another aim was to describe what could be defined as a histological pattern highly suggestive of CMV infection even in the absence of the fundamental morphological lesion (viral inclusion bodies). Concentrating the use of these complementary techniques in biopsy specimens showing this histological pattern could increase the number of CMV hepatitis diagnoses less expensively than their routine use in all liver allograft biopsy specimens.

\section{Methods}

Over a three year period, 244 consecutive OLTs were performed on a group of 198 patients. This study does not include those patients and grafts surviving for less than 15 days or those for which follow up biopsy specimens were not available to avoid diluting the true incidence of CMV hepatitis in recipients surviving through the period of greatest risk. Patients who had received prophylactic antiviral treatment were also excluded. Immunosuppressive therapy after transplantation was as follows: methylprednisolone, $200 \mathrm{mg} / \mathrm{dl}$ decreased gradually to $30 \mathrm{mg} / \mathrm{dl}$ for one month; cyclosporin, at doses adjusted to maintain its trough levels at $200-300 \mathrm{mg} / \mathrm{ml}$ in blood, and azathioprine ( $2 \mathrm{mg} / \mathrm{kg} /$ day). Initial rejection episodes were treated with three consecutive intravenous doses of methylprednisolone $(1 \mathrm{~g})$. If no histological response was obtained, OKT3 (Ortho Pharmaceuticals, Raritan, New Jersey, USA) was administered intravenously every day for 14 days.

Liver biopsies were routinely performed immediately after revascularisation of the liver allograft and two weeks after transplantation. If liver allograft dysfunction occurred, additional biopsy specimens were taken to establish a diagnosis. Liver biopsy was also carried out in those cases in which no biochemical response

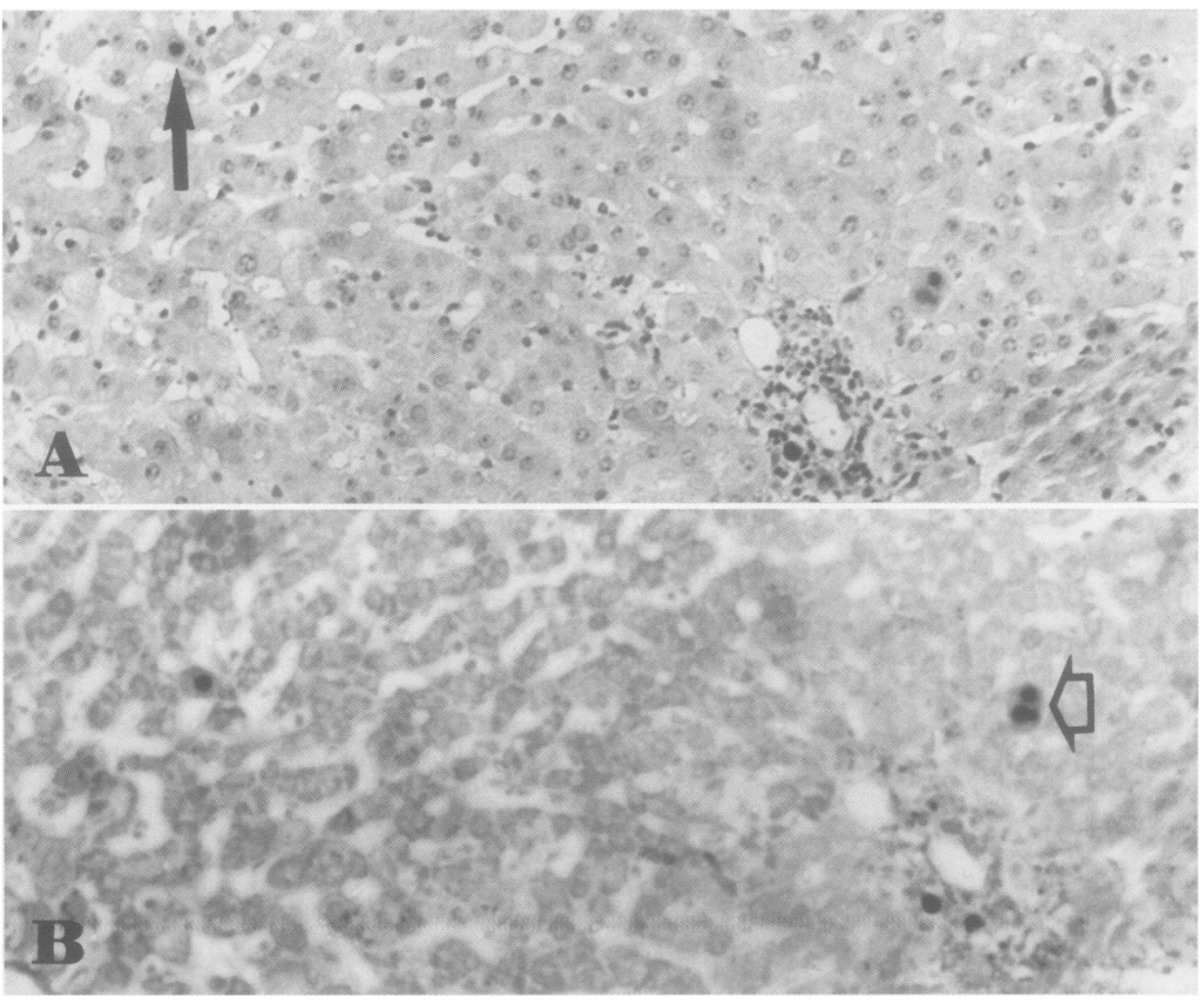

Figure 1 Immunohistochemistry. A: Three positive cells associated with a histological picture of rejection and no lobular inflammatory infiltrate. Black arrow shows a positive, morphologically normal cell $(\times 40)$. B: Positive nuclear and cytoplasmic inclusions (open arrow). Note the high degree of the immunostaining in the "normal" nucleus in this uncounterstained slide $(\times 40)$. 


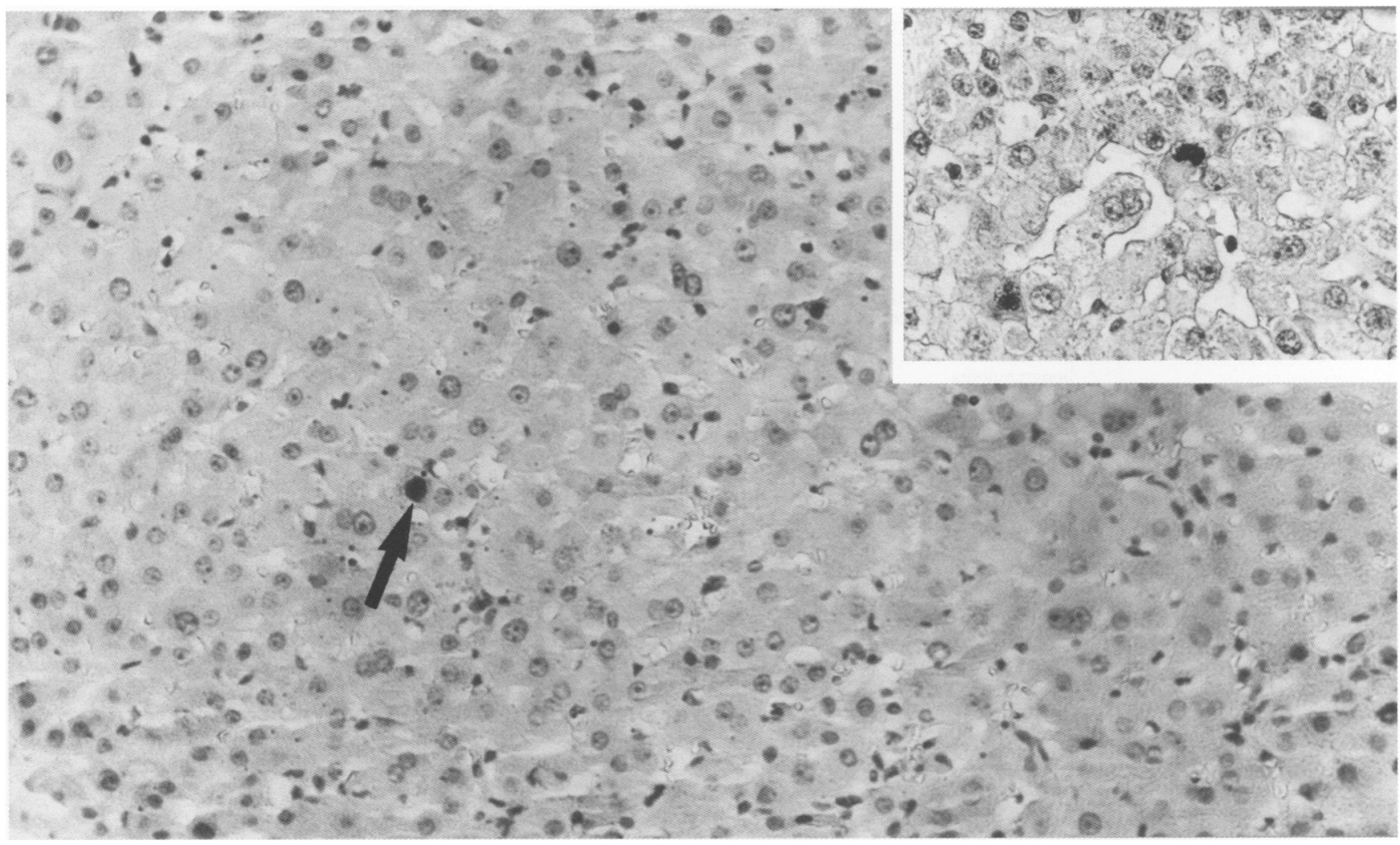

Figure 2 In situ hybridisation showing morphologically normal positive cells (arrow) in a specimen with disseminated focal hepatitis ( $\times$ 40). Inset: inclusion bodies also stained positively $(\times 400)$.

was observed in liver function tests after antirejection treatment and occasionally as a control after normalisation of liver function tests. The histopathological material available for this study came from 160 patients in whom a total of 191 OLTs were performed, with a mean histological follow up of $416 \pm 324$ days (last biopsy), yielding a total of 1022 liver biopsy specimens. The prospective study was carried out on 853 percutaneous Menghini needle paraffin wax embedded liver biopsy specimens after excluding 169 specimens obtained immediately after revascularisation. At least three haematoxylin and eosin stained sections with more than three portal tracts/biopsy were examined. Immunohistochemical studies were performed with monoclonal anti-CMV antibodies (clone $\mathrm{CCH} 2$ which recognises early and late antigens (Dako-CMV, code M757; Gostrup, Denmark)) in a single section. Immunohistochemical staining was carried out using $\mathrm{ABC}$ standard techniques. ${ }^{1718} \mathrm{~A}$ section of lung with CMV pneumonitis served as a positive control.

Two groups were selected from among the 853 biopsy specimens taken: group A, 23 specimens previously displaying viral inclusion bodies were re-cut. Immunohistochemistry and ISH with a CMV specific complementary DNA probe (Enzo-Pathogene, 32872; Syosset, New York, USA) were applied to this group, as reported elsewhere. ${ }^{19}$ Positive controls were also used. The following histological features were tabulated to characterise the histological pattern most frequently associated with viral inclusion bodies ${ }^{91020-24}$ : presence of disseminated inflammatory foci, types of foci classified according to their inflammatory cell population, diffuse sinusoidal lymphocytic infiltration, presence of hepatocytic anisokaryosis, hyperchromatism and anisocytosis, density of the inclusion bodies (number/haematoxylin and eosin section), and type of cell infected. The percentages of biopsy specimens for which immunohistochemistry and ISH tested positive were evaluated. Group B: recuts of the 34 biopsy specimens displaying the abovementioned histological patterns in the absence of viral inclusion bodies were also studied using immunohistochemistry and ISH.

Conventional culture and rapid shell vial culture $^{25}$ for CMV detection were carried out on biological products (blood, urine, exudates) of 82 patients (122 OLTs) (once a week until day 60 and thereafter once a month or whenever warranted by the patient's clinical condition).

Statistical analysis-Results are presented as mean $\pm S D$ time of diagnosis. Univariate analysis was performed by the $\chi^{2}$ test for categorical variables and Fisher's exact test when data were sparse. Comparative analysis of mean times of first positive biopsy specimens by different histological techniques was performed by the Kapan-Meier test (table 1); p $<.05$ was considered significant.

\section{Results}

CMV was detected by one or more of the three methods in 35 liver allograft biopsy specimens from $27(16.9 \%)$ patients (table 1$)$. The mean time for the first diagnosis of CMV hepatitis was $46 \pm 19$ days following surgery (range 21-114). Statistical comparison of the mean post-trans- 
Table 2 Histopathological characterisation of CMV hepatitis

\begin{tabular}{|c|c|c|c|c|}
\hline Histopathological features & $\begin{array}{l}\text { Group A } \\
(n=23)\end{array}$ & $(\%)$ & $\begin{array}{l}\text { Group B } \\
(n=34)\end{array}$ & $(\%)$ \\
\hline \multicolumn{5}{|l|}{ Location of inclusions bodies } \\
\hline hepatocyte & 23 & $(100)$ & & - \\
\hline nuclear & 3 & $(13 \cdot 0)$ & & - \\
\hline cytoplasmic & 0 & $(0.0)$ & & - \\
\hline both & 20 & $(87 \cdot 0)$ & & - \\
\hline biliary epithelium & 4 & $(17 \cdot 4)$ & & - \\
\hline endothelial or sinusoidal cell & 6 & $(26 \cdot 1)$ & & - \\
\hline \multirow{6}{*}{$\begin{array}{l}\text { Disseminated focal hepatitis } \\
\text { type of inflammatory cells in foci } \\
\text { mixed } \\
\text { neutrophilic } \\
\text { lipogranuloma } \\
\text { granuloma } \\
\text { pure lymphocytic }\end{array}$} & 21 & $(91 \cdot 3)$ & 34 & $(100)$ \\
\hline & 17 & $(73.9)$ & 17 & $(50 \cdot 0)$ \\
\hline & 8 & $(34 \cdot 8)$ & 12 & $(35 \cdot 3)$ \\
\hline & 2 & $(8 \cdot 7)$ & 1 & $(2.9)$ \\
\hline & $\mathbf{1}$ & $4 \cdot 3)$ & 4 & $(11 \cdot 8)$ \\
\hline & 0 & $(0.0)$ & 6 & $(17 \cdot 6)$ \\
\hline \multicolumn{5}{|l|}{ Other features } \\
\hline diffuse lymphocytic infiltration & 1 & $(4 \cdot 3)$ & 3 & $(9 \cdot 7)$ \\
\hline anisocytosis & 12 & $(52 \cdot 2)$ & 20 & ( $58 \cdot 8)$ \\
\hline anisokaryosis & 9 & $(39 \cdot 1)$ & 13 & $(38 \cdot 2)$ \\
\hline hyperchromatism & 14 & $(60.9)$ & 15 & $(44 \cdot 1)$ \\
\hline mitosis & 10 & $(43.5)$ & 11 & $(32 \cdot 4)$ \\
\hline
\end{tabular}

* Several biopsy specimens showed more than one type of inflammatory foci in their disseminated focal hepatitis pattern.

Table 3 Distribution of positive biopsy specimens by positive cell density

\begin{tabular}{lllllll}
\hline & \multicolumn{2}{l}{$\begin{array}{l}\text { Haematoxylin and eosin } \\
n(\%)\end{array}$} & $\begin{array}{l}\text { Immunohistochemistry } \\
n(\%)\end{array}$ & \multicolumn{2}{l}{$\begin{array}{l}\text { In situ hybridisation } \\
n(\%)\end{array}$} \\
\hline Total number of positive biopsy specimens & 23 & $(100 \%)$ & 29 & $(100 \%)$ & 17 & $(100 \%)$ \\
<5 cells/biopsy & 12 & $(52 \cdot 2)$ & 16 & $(55 \cdot 2)$ & 11 & $(64 \cdot 7)$ \\
5-10 cells/biopsy & 7 & $(30 \cdot 4)$ & 3 & $(10 \cdot 3)$ & 4 & $(23 \cdot 5)$ \\
$>10$ cells/biopsy & 4 & $(17 \cdot 4)$ & 10 & $(34 \cdot 5)$ & 2 & $(11 \cdot 8)$ \\
\hline
\end{tabular}

plant time (Kaplan-Meier test) for the initial diagnosis of CMV hepatitis by each of the techniques did not reveal significant differences (table 1). Recurrence of CMV hepatitis was observed (by immunohistochemistry) in one patient at day 373 post-transplant (333 days after a previous biopsy had confirmed CMV hepatitis, but the next three biopsy specimens were negative for CMV). Another patient was only diagnosed as CMV positive by immunohistochemistry in a biopsy specimen taken on day 114 post-transplant. Excluding this outlier, the initial time of diagnosis by immunohistochemistry was $44 \pm 13$ days (range 23-73), which was not statistically significant with respect to the mean time for diagnosing the total series (table 1).

Of the 35 biopsy specimens with CMV documented by one of the three methods, 29 were positive by immunohistochemistry (sensitivity $=0 \cdot 83$ ) and 23 (group A) demonstrated viral inclusion bodies in the haematoxylin and eosin stained sections (sensitivity $=0.66$ ) (table 1). It should be noted that in the prospective study of 853 biopsy specimens, immunohistochemistry was positive in four specimens in which staining with haematoxylin and eosin did not detect viral inclusion bodies and which did not have the inflammatory lesion described in groups A or B. Of the 23 group A biopsy specimens, immunohistochemistry was positive in $19(82 \cdot 6 \%)$. The inclusion bodies displayed in these new sections appeared to stain immunohistochemically but morphologically normal cells also stained occasionally (fig 1). In four of the specimens the new sections to which immunohistochemistry was applied displayed neither inclusion bodies nor morphologically normal positive cells and were regarded as false negative results. Immunohistochemistry was positive in two patients without liver dysfunction, whose allografts had been biopsied to check for resolution of cellular rejection, but no positive culture developed in blood, throat and bronchoalveolar exudates, or urine samples obtained at the same time as the graft biopsy. Rejection induced cellular infiltration disappeared after additional immunosuppressive treatment and only the finding of CMV antigens in liver tissue by immunohistochemistry could be considered pathological. ISH was positive in $14(60.9 \%)$ of the 23 group A and in two of the group B specimens. This technique also demonstrated, although very infrequently, positive cells without morphological lesions (cytomegalic and/or inclusion) in both groups (fig 2 ).

The histological characteristics of the 23 group A specimens are detailed below (table 2). Viral inclusion bodies: hepatocytes were being most frequently affected with nuclear $(100 \%)$ and/or cytoplasmic inclusion bodies $(87 \%)$. The density of inclusion bodies per biopsy varied widely $(52 \%$ of the specimens presented with less than five cells with viral inclusion bodies per histological section) (table 3). Demonstration of a single inclusion body occurred regularly (five specimens). Numerous inflammatory foci scattered throughout the liver tissue (termed disseminated focal hepatitis) (fig 3) were present in $91 \%$ of the group A specimens (table 2). The inflammatory foci were sometimes located around cells carrying viral inclusion bodies but often no such proximity to these cytomegalic cells was evident. Cells with inclusion bodies not surrounded by inflammatory infiltrate were also observed. Three types of foci were characterised (fig 4): 


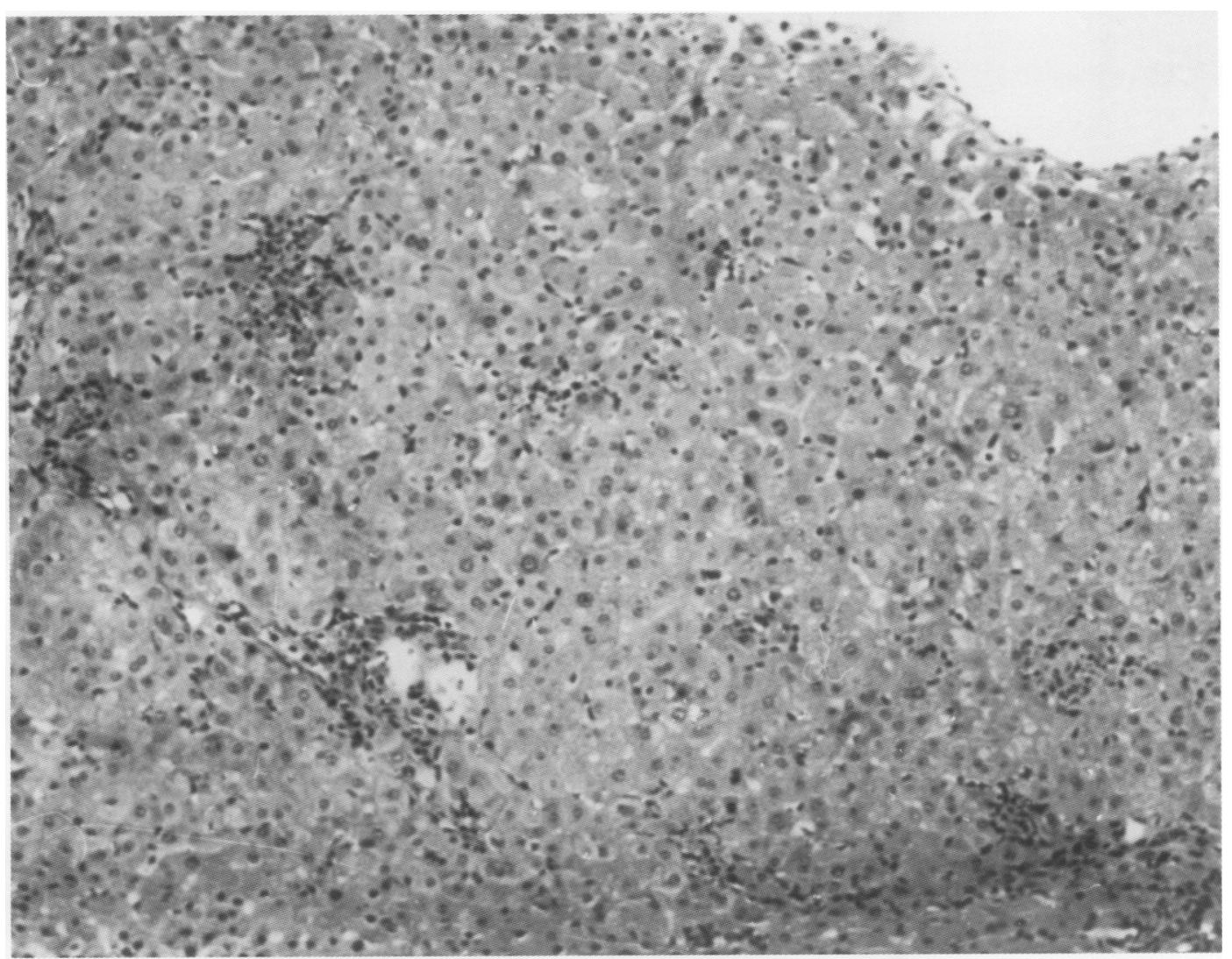

Figure 3 Disseminated focal hepatitis. Multiple inflammatory foci do not show preferential zonal localisation in the lobule (haematoxylin and eosin, $\times 40$ ).

pure polymorphonuclear leucocytes, mixed polymorphonuclear leucocytes and round cells (macrophages, lymphocytes, plasma cells), and granulomatous foci. In $34 \cdot 8 \%$ of cases coincident foci of these three types could be observed heterogeneously distributed in the same section with no defined preferential zonal location in the hepatic lobule. Anisocytosis, anisokaryosis, hyperchromatism, and mitosis of the hepatocytes were frequent histological changes accompanying the inflammatory histological pattern. Diffuse sinusoidal lymphocytic infiltration with a mononucleosis-like pattern was observed in only one specimen in this group (table 2).

In group B specimens disseminated focal hepatitis was detected a mean of $69 \pm 63$ days post-transplant, which was not significantly different to that for the $35 \mathrm{CMV}$ positive specimens $(59 \pm 57$ days) (table 1$)$. Nor were there statistically significant differences ( $\chi^{2}$ test) between the incidence of the histological features observed in groups A and B (table 2). Eight $(23.5 \%)$ of the 34 biopsy specimens with disseminated focal hepatitis without viral inclusion bodies were positive by immunohistochemistry $(n=6)$ or by ISH $(n=2)$. Another $12(35.3 \%)$ specimens from this group were taken from allografts which were CMV positive in previous or subsequent biopsy specimens.

\section{Discussion}

CMV hepatitis was defined as invasive CMV infection of the liver with histological evidence of a viral cytopathic effect. ${ }^{12}$ It is a common cause of complications among immuno- suppressed OLT recipients. ${ }^{5}$ Liver biopsy is an important tool for diagnosing the causes of liver allograft dysfunction and can differentiate CMV hepatitis from cellular rejection. Other microscopic diagnoses are possible as very little overlap exists between the inflammatory response provoked by $\mathrm{CMV}$ and other simultaneous processes. ${ }^{1026}$ The incidence of CMV hepatitis in the series studied here was $16.8 \%$. The period of maximum risk was within $46 \pm 19$ days post-transplant. Recurrence of CMV hepatitis was rare (one case), as was late onset (one case: day 114). The presence of viral inclusion bodies in liver tissue correlated with active disease in most cases, as has been reported in other series. ${ }^{6}$ Histological study has also been reported to offer greater sensitivity than rapid shell vial culture, ${ }^{13}$ however, Paya et $a l^{6}$ detected CMV hepatitis on culture of biopsy specimens (viral inclusion bodies present) but these same specimens were negative on histology. This apparent anomaly could be explained by the focal and scarce distribution of infected cells in some of the biopsied allografts (table 3 ).

If used on all liver allograft biopsy specimens, immunohistochemistry is more sensitive than histological demonstration of inclusion ${ }^{1316}$ (29 $v 23$ in this study). Unlike other studies, ${ }^{1527}$ in this series immunohistochemistry did not provide early warning of CMV infection, which can be attributed in part to the focal and scarce distribution of positive cells on immunohistochemistry. The possibility of easily studying more re-cut sections by staining with haematoxylin and eosin than just one or two by immunohistochemistry and ISH could also explain the false negative results produced with 

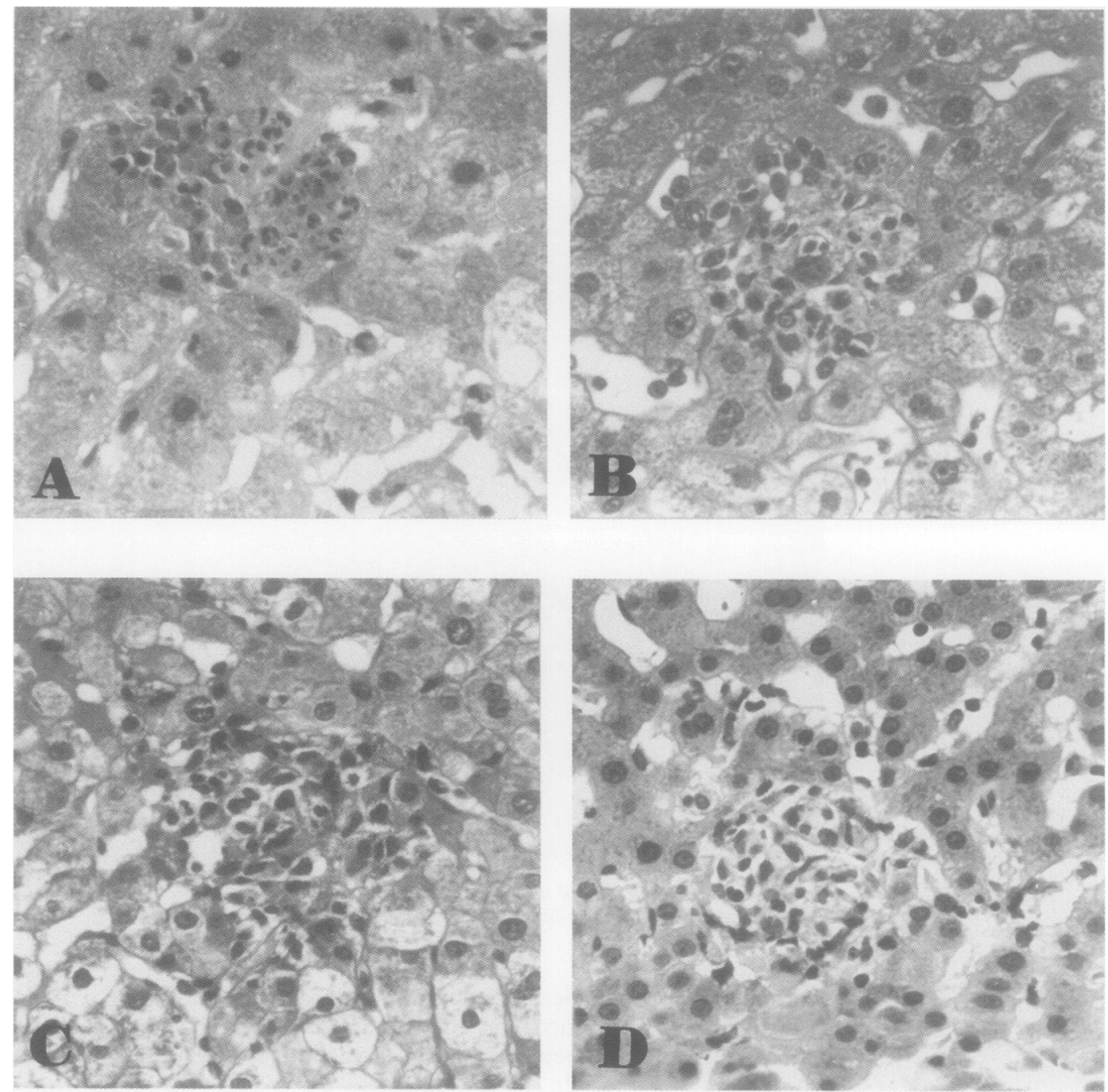

Figure 4 Types of inflammatory foci: A: pure neutrophilic; B: mixed around a cytomegalic inclusion body; $C$ : neutrophils, plasma cells and lymphocytes; D: granulomatous (haematoxylin and eosin, $\times 100)$.

the latter two methods. In some series, ${ }^{28}$ as was the case in ours, ISH has found to be less sensitive, ${ }^{1419}$ although its use may increase the number of diagnoses. One possible explanation of the greater sensitivity of immunohistochemistry compared with ISH is that the former can detect more cells harbouring viral products (antigens), which could be more numerous than cells holding viral DNA. ${ }^{12}{ }^{13}$ ISH, on the other hand, demonstrates viral DNA and therefore identifies cells with active replication. ${ }^{1422}$ Intracellular or extracellular influences (such as oestrogens) can modulate or alter the CMV replication cycle and thus explain why not all infected cells host full viral replication and/or harbour inclusion bodies. ${ }^{29} 30$

The indiscriminate application of all of these diagnostic methods to liver allograft biopsy specimens is time-consuming and expensive. The disseminated focal hepatitis pattern, such as the one evaluated in this study, could be useful as a basis for selecting biopsy specimens for subsequent examination using immunohistochemistry and/or ISH and serve as a guideline for histopathology laboratories. As was the case in this study, Paya et $a l^{13}$ have reported biopsy specimens with a disseminated focal necrosis pattern accompanied by CMV vir- emia, although they could not always confirm the presence of CMV in the tissue using immunohistochemistry. The presence of so-called disseminated focal hepatitis on histology should spark a search for CMV. An algorithm is proposed for determining when such techniques can be effectively used (fig 5). The time posttransplant during which patients are at increased risk of CMV infection $(46 \pm 19$ posttransplant days) is another parameter which should be borne in mind when deciding on the additional use of ISH and/or immunohistochemistry on histological sections.

Demonstration of infected liver allograft cells using immunohistochemistry in the absence of allograft dysfunction or a histological inflammatory lesion and negative on culture, raised questions as the validity of certain accepted methods of diagnosing CMV hepatitis. The great sensitivity of immunohistochemistry $^{31}$ and other new techniques such as $\mathrm{PCR}^{32}$ for detecting antigens or genomes of latent viruses (permanent infection without replication or disease) makes it advisable that the clinician be informed as to whether or not CMV positive results on the above methods coincide with microscopic lesions on staining with haematoxylin and eosin. 


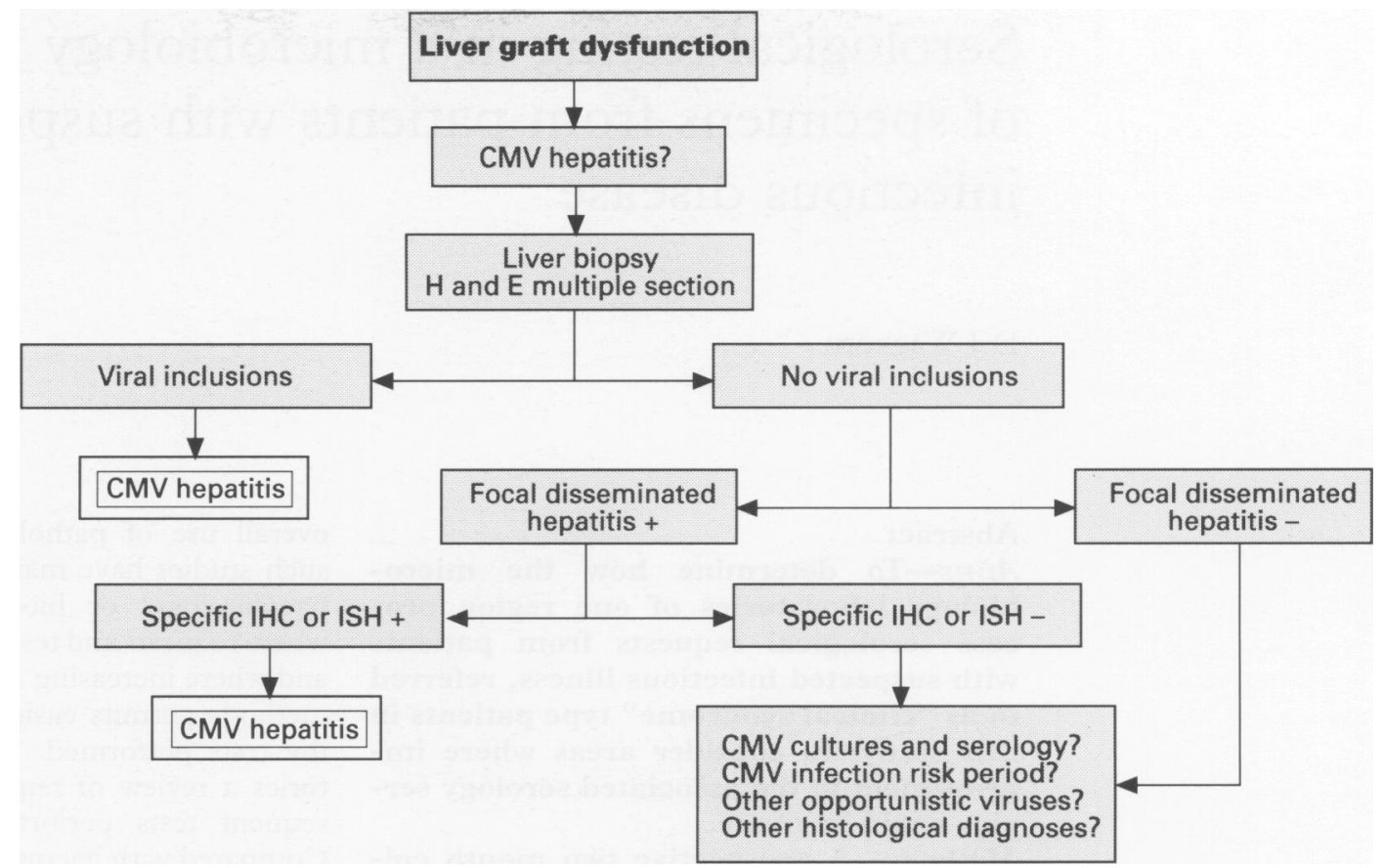

Figure 5 Proposed algorithm for diagnosing CMV hepatitis in liver grafts. IHC, immunohistochemistry; $H$ and $E$, haematoxylin and eosin.

This work was supported by a research grant (94/0242) from the Fondo de Investigaciones Sanitarias, Ministry of Health, Madrid, Spain. N T Jucá was sponsored by the Conselho Nacional de Desenvolvimento Científico e Tecnológico de Brasil. Preliminary results were presented in 1993 at the XVI National Congress of the Sociedad Española de Anatomía Patológica, Tenerife, Spain.

1 Ho M. Human cytomegalovirus infections in immunosuppressed patients. In: Cytomegalovirus. Biology an infection. New York: Plenum Press, 1991:249-300.

2 Ho M. Cytomegalovirus infection and indirect sequelae in immunocompromised transplant patients. Transplant Proc 1991;23 (Suppl 1):2-7.

3 Rubin RH. The indirect effects of cytomegalovirus infection on the outcome of organ transplantation. $\mathscr{f} A M A 1989$; 261:3607-9.

4 Rubin RH. Impact of cytomegalovirus infection on organ tranplant recipients. Rev Infect Dis 1990;12 (Suppl 7): 754-66.

5 Stratta RJ, Shaeffer MS, Markin RS, Wood RP, Langnas $\mathrm{AN}$, Reed EC, et al. Cytomegalovirus infection and disease after liver transplantation. An overview. Dig Dis Sci 1992; 37:673-88.

6 Paya CV, Hermans PE, Wiesner RH, Ludwig J, Smith TF, Rakela J, et al. Cytomegalovirus hepatitis in liver transplantation: Prospective analysis of 93 consecutive orthotopic liver transplantations. F Infect Dis 1989;160: orthoto $752-8$.

7 Rakela J, Wiesner RH, Taswell HF, Hermans PE, Smith TF, Perkins JD, et al. Incidence of cytomegalovirus in$\mathrm{TF}$, Perkins $\mathrm{JD}$, et al. Incidence of cytomegalovirus in-
fection and its relationship to donor-recipient serologic fection and its relationship to donor-recipient serologic
status in liver transplantation. Transplant Proc 1987;19: status in liver

8 Singh N, Dummer JS, Kusne S, Breinig MK, Armstrong $\mathrm{JA}$, Makowka L, et al. Infections with cytomegalovirus and other herpes viruses in 121 liver transplant recipients: transmission by donated organ and the effect of OKT3 antibodies. F Infect Dis 1988;158:124-31.

9 Snover DC, Hutton S, Balfour HH Jr, Bloomer JR. Cytomegalovirus infection of the liver in transplant recipients. 7 Clin Gastroenterol 1987;9:659-65.

10 Bronsther O, Makowka L, Jaffe R, Demetris AJ, Breinis MK, Ho M, et al. Occurrence of cytomegalovirus hepatitis in liver transplant patients. $\mathcal{f}$ Med Virol 1988;24:423-34.

11 Paya CV, Wiesner RH, Hermans PE, Larson-Keller JJ, Ilstrup DM, Krom RAF, et al. Risk factors for cytomegalovirus and severe bacterial infections following live transplantation: A prospective multivariate time-dependent analysis. $\mathcal{f}$ Hepatol 1993;18:185-95.

12 Stratta RJ, Shaefer MS, Markin RS, Wood RP, Kennedy EM, Langnas AN, et al. Clinical patterns of cytomegalovirus disease after liver transplantation. Arch Surg 1989;124:1443-50.

13 Paya CV, Holley KE, Wiesner RH, Balasubramaniam K, Smith TF, Espy MJ, et al. Early diagnosis of cytomegalovirus hepatitis in liver transplant recipients: Role of immunostaining, DNA hybridization and culture of hepatic tissue. Hepatology 1990;12:119-26.

14 Naoumov NV, Alexander GJ, O'Grady JG, Sutherland S, Aldis P, Portmann BC, et al. Rapid diagnosis of cytoAldis P, Portmann BC, et al. Rapid diagnosis of cytomegalovirus infection by in-
grafts. Lancet 1988;i:1361-4.
15 Theise ND, Conn M, Thung SN. Localization of cytomegalovirus antigens in liver allografts over time. Hum Pathol 1993;24:103-8.

16 Niedobitek G, Finn T, Herbst H, Gerdes J, Grillner L, Landqvist $M$, et al. Detection of cytomegalovirus by in situ hybridisation and immunohistochemistry using new monoclonal antibody CCH2: a comparison of methods. monoclonal antibody Pathol 1988;41:1005-9.

17 Hsu SM, Raine L, Fanger H. Use of avidin-biotin-peroxidase complex (ABC) in immunoperoxidase techniques: $A$ comparison between $\mathrm{ABC}$ and unlabeled antibody (PAP) procedures. F Histochem Cytochem 1981;29:577-80.

18 Zweygberg-Wirgart B, Landqvist M, Hökeberg I, Eriksso BM, Oldin-Stenkvist E, Grillner L. Early detection of cytomegalovirus in cell culture by a new monoclonal antibody CCH2. $₹$ Virol Methods 1990;27:211-19.

19 Masih AS, Linder J, Shaw BW Jr, Wood RP, Donovan JP, White $\mathrm{R}$, et al. Rapid indentification of cytomegalovirus in liver allograft biopsies by in situ hybridisation. $A m \mathcal{F}$ Surg Pathol 1988;12:362-7.

20 Reller LB. Granulomatous hepatitis associated with acute cytomegalovirus infection. Lancet 1973;i:20-2.

21 Bonkowsky HL, Lee RV, Klatskin G. Acute granulomatous hepatitis: occurrence in cytomegalovirus mononucleosis. FAMA 1975;233:1284-8.

22 Ten Napel CHH, Houthoff HJ, Teh TH. Cytomegalovirus hepatitis in normal and immune compromised hosts. Liver 1984;4:184-94.

23 Colina F, Mollejo M, Moreno E, Alberti N, García I Gómez-Sanz R, et al. Effectiveness of histopathological diagnoses in dysfunction of hepatic transplantation. Review of 146 histopathological studies from 53 transplants Arch Pathol Lab Med 1991;115:998-1005.

24 Snover DC. Biopsy diagnosis of liver disease. Baltimore: Williams and Wilkins, 1992:127-54

25 Paya CV, Smith TF, Ludwig J, Hermans PE. Rapid shell vial culture and tissue histology compared with serology for the rapid diagnosis of cytomegalovirus infection in for the rapid diagnosis of cytomegalovirus infection
liver transplantation. Mayo Clin Proc 1989;64:670-5.

26 Colina F. The role of histopathology in hepatic transplantation. Semin Diagn Pathol 1992;9:200-9.

27 Rabah R, Jaffe R. Early detection of cytomegalovirus in the allograft liver biopsy: A comparison of methods. Pediat Pathol 1987;7:549-56.

28 Espy MJ, Paya CV, Holley KE, Ludwig J, Hermans PF Wiesner RH, et al. Diagnosis of cytomegalovirus hepatitis by histopathology and in situ hybridisation in liver transplantation. Diagn Microbiol Infect Dis 1991;14:293-6.

29 Lafemina RL, Hayward GS. Differences in cell-type-specific blocks to immediate early gene expression and DNA replication of human, simian, and murine cytomegalovirus. f Gen Virol 1988;69:355-74.

30 Koment RW. Restriction to human cytomegalovirus replication in vitro removed by physiological levels of cortisol. f Med Virol 1989;27:44-7.

31 Toorkey CB, Carrigan DR. Immunohistochemical detection of an immediate early antigen of human cytomegalovirus in normal tissues. $\mathcal{F}$ Infect Dis 1989;160:741-51.

32 Delgado R, Lumbreras C, Alba C, Pedraza MA, Otero JR Gómez $\mathrm{R}$, et al. Low predictive value of polymerase chain reaction for diagnosis of cytomegalovirus disease in liver transplant recipients. $\mathcal{f}$ Clin Microbiol 1992;30:1876-8. 